\title{
Saliva Leptin Levels in Tooth Movement during Initial Stage of Orthodontic Alignment: A Pilot Study
}

\author{
Noraini Abu Bakar ${ }^{\star *}$, Wisam Kamil ${ }^{2}$, Lina Al Bayati ${ }^{3}$, \\ Basma Ezzat Mustafa ${ }^{4}$
}

1 Orthodontic Department, Dental Faculty, International Islamic. University Malaysia, Pahang, MALAYSIA

${ }^{2}$ Periodontics Department, Dental Faculty, International Islamic. University Malaysia, Pahang, MALAYSIA

${ }^{3}$ Periodontics Department, Dental Faculty, International Islamic University Malaysia, Pahang, MALAYSIA

${ }^{4}$ Basic Medical Science Department, Dental Faculty, International Islamic University Malaysia, Pahang, MALAYSIA

Corresponding authors: Asst Prof Dr Noraini Abu Bakar DDS(USM), MSc

Orthodontics(London), MOrth RCS (Edinburgh) Head of Paediatric Dentistry, Orthodontics and Dental Public Health Department

Dental Faculty, International Islamic University Malaysia

Kuantan Campus,

25200 Kuantan

Pahang, MALAYSIA

Email: nor_aini@iium.edu.my

Phone:600127140094

Received: May 22, 2017

Accepted: September 20, 2017
Abstract: During orthodontic tooth movement, the early response of periodontal tissues to mechanical stress is an acute inflammatory reaction. Mechanical stress from orthodontic appliances is believed to induce cells in the periodontal ligament (PDL) to form biologically active substances, such as enzymes and cytokines, responsible for connective tissue remodeling (Nishijima $Y$ et al 2006). Leptin, a polypeptide hormone has been classified as a cytokine (Zhang et al 1994). Earlier findings concluded that leptin at high local concentrations protects the host from inflammation and infection as well as maintaining bone levels. It has been also suggested that leptin plays a significant role in bone formation by its direct effect on osteoblasts (Alparslan et al 2010). This pilot study aimed to study leptin in saliva and its association with tooth movement during initial orthodontic alignment. Aim: To determine if there are any differences in saliva leptin level before and after orthodontic alignment. Methods: Ten orthodontic patients ( 7 girls and 3 boys; mean age, $16.76 \pm 1.1$ years) with crowding (up to $5 \mathrm{~mm}$ ) that required orthodontic fixed appliances, on a non-extraction basis as part of the treatment plan, were recruited in this longitudinal study. Orthodontic study models were constructed at baseline and at 6 - weeks after orthodontic treatment commenced. Full fixed orthodontic appliances with initial 0.014" Nickel Titanium archwire placed. The amount of crowding was measured, before and after initial alignment with an electronic digital caliper (Max-Cal, Japan Micrometer Ltd, Tokyo, Japan) with an accuracy of up to $0.01 \mathrm{~mm}$. Unstimulated morning saliva sample were collected at all visits, after at least an 8-hour period of fasting and no-toothbrushing. After centrifugation (4000x g;10min), the samples were stored at $-25 \mathrm{C}$ and tested using Leptin Abnova LEP Human ELISA kit (KA3080) which was subsequently 
analyzed. Subjects' periodontal health status was also monitored throughout the study. Ethical approval (ID IREC 262) was received on $7^{\text {th }}$ April 2014 from International Islamic University Malaysia Research Ethics Committee (IREC). Results: Leptin concentration in saliva was significantly decreased in a time-dependant manner $(t(9)=8.60, p<0.001)$, from before orthodontic treatment $(7016.45 \pm 425.15 \mathrm{pg} / \mathrm{mL})$ and 6 weeks after bond-up $(4901.92 \pm 238.64 \mathrm{pg} / \mathrm{mL})$. Conclusion: Leptin concentration in saliva is decreased during orthodontic tooth movement in initial alignment stage.

Keywords: Leptin, saliva, tooth movement

\section{Introduction}

Leptin is a highly hydrophilic protein that circulates in plasma as a 16-kDa protein. It is produced in adipose tissue and also recently described to be synthesized by placental tissue. Plasma concentration of leptin is positively correlated to body fat mass, and administration of recombinant leptin to mice indicates that leptin participates in the regulation of food intake and energy expenditure.

Leptin is released primarily by adipose tissue, and it is strongly correlated with body weight and body fat mass ${ }^{1}$. Leptin has been reported to influence various biological mechanisms, including the immune and inflammatory response, haematopoiesis, angiogenesis, bone formation, and wound healing2; it also has an anti-inflammatory action ${ }^{3}$. It has been reported that serum leptin levels were increased by surgical stress and acute sepsis. In these states, increased stress-induced hormones and cytokines, such as cortisol, TNF-a, IL-1, and IL-6 have been thought to cause the increment of serum leptin level ${ }^{4}$.

Since the discovery of this relatively new hormone, many studies have been conducted to know more about its role in various fields. This includes leptin's role in regulating bone metabolism that was first described in year $2000^{5}$. Leptin was also associated with inflammatory response including periodontitis. It has been suggested that the salivary leptin concentration significantly changed in chronic periodontitis patients and may reflects the disease activity ${ }^{6}$.

Leptin was classified as a cytokine ${ }^{7}$ that plays a role in the host defense immune system where stimulates the immune system by enhancing pro-inflammatory cytokine production and phagocytosis by macrophages ${ }^{1}$. This was further supported by the study of Bozkurt 2006, who suggested that an elevated level of leptin in gingival crevicular fluid of healthy periodontium prolonging the life span of human primary osteoblasts by inhibiting apoptosis ${ }^{8}$.

It is assumed that leptin has a role in protecting gingival tissues ${ }^{9}$, leptin stimulates the immune system and enhances bone formation by acting directly on osteoblasts ${ }^{10}$. As periodontal disease progresses, the protective role of leptin on the gingiva is lost owing to a decrease in the leptin level.

During orthodontic tooth movement, the early response of periodontal tissues to mechanical stress is an acute inflammatory reaction ${ }^{11}$.

Remodeling process (resorption and apposition) takes place in periodontal tissues induced by the changes in the stress-strain distribution in the periodontium after the 
application of orthodontic forces ${ }^{12}$. Furthermore, a local damage-repair process with inflammation-like reactions, including high vascular activity with many leukocytes and macrophages and involvement with the immune system may occur during orthodontic tooth movement ${ }^{5}$. Changes in the stress-strain distribution in the periodontium after the application of orthodontic forces trigger remodelling processes. These forces compress the PDL fibers and reduce the PDL space in the pressure area. At the tension site, PDL fibers are stretched, and orthodontic force results in widening of the periodontal membrane ${ }^{13}$

Study of leptin therefore is a useful guide to determine its relationship with tooth movement in both tension and pressure sites and the role of this cytokine in controlling the local inflammation around the tooth. Detection of the leptin level in GCF at sites under orthodontic movement had been tested and it was found that the concentration of leptin in GCF is decreased by orthodontic tooth movement ${ }^{12}$

This pilot study aimed to venture leptin in saliva and its association with tooth movement during initial orthodontic alignment. The specific aim is to determine if there is any differences in saliva leptin level before and after orthodontic alignment

\section{Material and methods:}

A convenient sampling of ten orthodontic patients ( 7 girls and 3 boys; mean age, $16.76 \pm 1.1$ years) were selected according to the inclusion criteria. Ethical approval with ID No IREC 262 received from International Islamic University Malaysia Research Ethics Committee (IREC).

Inclusion criteria were:

- Patients with mild to moderate crowding (up to $5 \mathrm{~mm}$ ) malocclusion, requiring orthodontic treatment with fixed appliances on a non-extraction basis

- Good health

- Normal body mass index, according to the WHO chart (BMI of 18.5-22.9)

- No history of the use of anti-inflammatory drugs within the month preceding the sample collection

- No history of the use of antimicrobial therapy within the previous 6 months

- Healthy periodontal tissues with generalized probing depths of $\leq 2 \mathrm{~mm}$, with minimal bleeding and no sign of attachment loss

- No radiographic evidence of periodontal bone loss

Patients were identified in orthodontic specialist clinic, International Islamic University Malaysia. Patients who met the criteria were given ample information about the study in addition to the research information sheet. Informed consent obtained from patients who agreed to participate and patients' rights were protected according to Good Clinical Practice Guideline.

Subjects that met the inclusion criteria were seen in 3 appointments as shown in Table 1. 
Table 1. Procedures done and time frame of the three visits.

\begin{tabular}{|c|c|c|}
\hline Visit & Time frame & Actions \\
\hline \multirow{5}{*}{1} & \multirow{5}{*}{0 Week } & - $\quad$ Basic Periodontal Examination \\
\hline & & - $\quad$ First unstimulated saliva sample taken (Baseline) \\
\hline & & Scaling and polishing \\
\hline & & - Oral hygiene instructions given \\
\hline & & Impressions for baseline orthodontic study model taken \\
\hline \multirow{3}{*}{2} & \multirow{3}{*}{6 weeks after visit 1} & - $\quad$ Basic Periodontal Examination \\
\hline & & $\begin{array}{l}\text { - Second unstimulated saliva sample taken (using Felcon } \\
\text { sterile tube } 50 \mathrm{ml} \text { ) }\end{array}$ \\
\hline & & $\begin{array}{l}\text { Upper and lower orthodontic fixed appliances bonded } \\
\text { with } 0.014 \text { " Nickel Titanium wires ligated on both upper } \\
\text { and lower arch. }\end{array}$ \\
\hline \multirow{3}{*}{3} & \multirow{3}{*}{6 weeks after visit 2} & - $\quad$ Basic Periodontal Examination \\
\hline & & Third unstimulated saliva sample taken \\
\hline & & Impressions for second orthodontic study model taken \\
\hline
\end{tabular}

Morning, unstimulated whole saliva $(5 \mathrm{ml})$ sample were collected by a modified draining method ${ }^{14}$ as a diagnostic fluid, at all 3 visits. Patients were required to fast from midnight till the time the saliva samples were taken at 8 am (after at least 8 hours of fasting). Patients also were not allowed to brush the morning of the appointment as to avoid risks of gingival trauma/bleeding during sample collection. Participants were asked to expectorate into disposable tubes every $30 \mathrm{sec}$ over a period of $5 \mathrm{~min}$. After centrifugation(4000x g;10min), the samples were stored at $-25 \mathrm{C}$ and tested using Leptin Abnova LEP Human ELISA kit (KA3080).

At baseline visit, all the clinical periodontal parameters were measured with a Goldman/Fox Williams probe calibrated in millimetres by one trained dentist. These parameters include, bleeding on probing (BOP) and the plaque control index (PS), while probing pocket depth (PPD) was calculated as the measurement from gingival margin to the base of probing crevice. This was to ensure that subjects were free from periodontal diseases and as a tool to monitor periodontium status throughout the study.

As part of our routine pre orthodontic protocol, we implement professional plaque control, and all patients received full mouth supragingival supra and subgingival scaling using piezoelectric scaler with oral hygiene instruction including brushing twice a day using modified Bass brushing technique. All the clinical periodontal parameters have been re-evaluated 6 weeks after the scaling session and re-assessed 6 weeks after the orthodontics treatment.

Dental impressions for study models were taken before and after orthodontic treatment commenced. Full fixed orthodontic appliances(with MBT prescriptions) bonded with 0.014 " Nickel Titanium wires ligated on both upper and lower arches, 6 weeks after scaling was done.

Amount of crowding was evaluated by using an electronic digital caliper (Max-Cal, Japan Micrometer Ltd, Tokyo, Japan) with an accuracy of $0.01 \mathrm{~mm}$ over the occlusal surface of study models to measure the mesio-distal width of misaligned teeth 
and available space in the archform selected ${ }^{15}$. The same technique was applied to measure the amount of tooth movement 6 weeks after braces placement. The total amount of tooth movement was recorded in $\mathrm{mm}$.

Data was analyzed using IBM SPSS Statistics for Windows, Version 20.0 and a significance level was set at $95 \%(p \leq 0.05)$.Data was presented using mean and standard deviation (SD). Repeated measures ANOVA test was used to test mean differences between the three visits, while the Paired $t$-test was used to detect mean differences between two visits. $p<0.05$ was considered statistically significant.

\section{Results}

\section{Changes in periodontal parameters between the three visits}

The clinical periodontal parameters of 10 recruited patients were scored at the baseline visit and were 89.58(8.63), 61.36(12.20) and 1.91(0.18) for PS, BOP and PPD respectively. All patients' periodontal scores were slightly decreased at $2^{\text {nd }}$ visit after receiving nonsurgical periodontal treatment that includes supra and subgingival scaling using piezoelectric scaler with oral hygiene instruction including brushing twice a day using modified Bass brushing technique, but didn't reach the statistical significance as shown in Table 2. On the other hand the PS 90.30(8.78) and BOP 65.82(9.56) were increased after the orthodontics treatment compared to baseline and $2^{\text {nd }}$ visit, but $p$-value was statistically not significant. This result showed that all the patients' periodontium remains healthy throughout the study thus eliminating the possibility of leptin changes due to periodontitis.

\section{Changes in leptin level between the three visits}

Figure 1 shows the saliva leptin level between the three visits. As shown in Table 3, there was a statistically significant decrease in leptin level between visit $3(M=4901.923$, $S D=754.657)$ and visit $1(M=7016.457, S D=1344.468) ; t(9)=8.601, p=0.000$. There was also a statistically significant decrease in the number of leptin level between visit $1(M=7016.457, S D=1344.468)$ and visit $2(M=5018.528, S D=901.327) ; t(9)=8.312$, $p=0.000$. However, no significant difference was found between visit 2 and visit 3 $(t(9)=1.081, p>0.05)$.

Table 2. Changes in periodontal parameters from baseline to 6 weeks after bond-up

\begin{tabular}{lcccccc}
\hline Variables & $\begin{array}{c}\text { Baseline } \\
\text { (Visit 1) }\end{array}$ & $\begin{array}{c}2^{\text {nd }} \text { visit } \\
\text { (Visit 2) }\end{array}$ & $p$-value & $\begin{array}{c}3^{\text {rd }} \text { visit } \\
(\text { Visit 3) }\end{array}$ & $p$-value & $p_{\text {-value }}$ \\
\hline PS & $89.58(8.63)$ & $86.244(4.10)$ & 0.320 & $90.30(8.78)$ & 0.271 & 0.394 \\
\hline BOP & $61.36(12.20)$ & $60.085(13.63)$ & 0.759 & $65.82(9.56)$ & 0.170 & 0.317 \\
\hline PDV & $1.91(0.18)$ & $1.792(0.22)$ & 0.101 & $1.83(0.20)$ & 0.475 & 0.174 \\
\hline
\end{tabular}

Data are given as mean (standard deviation) unless stated otherwise.

PS: Percentage of sites with plaque scores

BOP: Percentage of sites with bleeding on probing

PPD: probing pocket depth

$¥$ : Repeated measures ANOVA test among three visits $\mathbf{q}$ : Paired $t$-test (between baseline and $2^{\text {nd }}$ visit)

$\S$ : Paired $t$-test (between $2^{\text {nd }}$ and $3^{\text {nd }}$ visits) 
Leptin concentrations decreased in a time-dependent manner during the study period. When compared with baseline, the decrease was statistically significantly 6 weeks after orthodontic alignment.

\section{Changes in tooth movement after initial alignment}

There was significant tooth movement between $1^{\text {st }}$ visit and $3^{\text {nd }}$ visit $(p<0.0001)$ as shown in Table 4. On average, the tooth movement were $2.20 \mathrm{~mm}$ (95\% Cl: 1.6357, 2.7643) 6 weeks after patients in initial alignment stage.

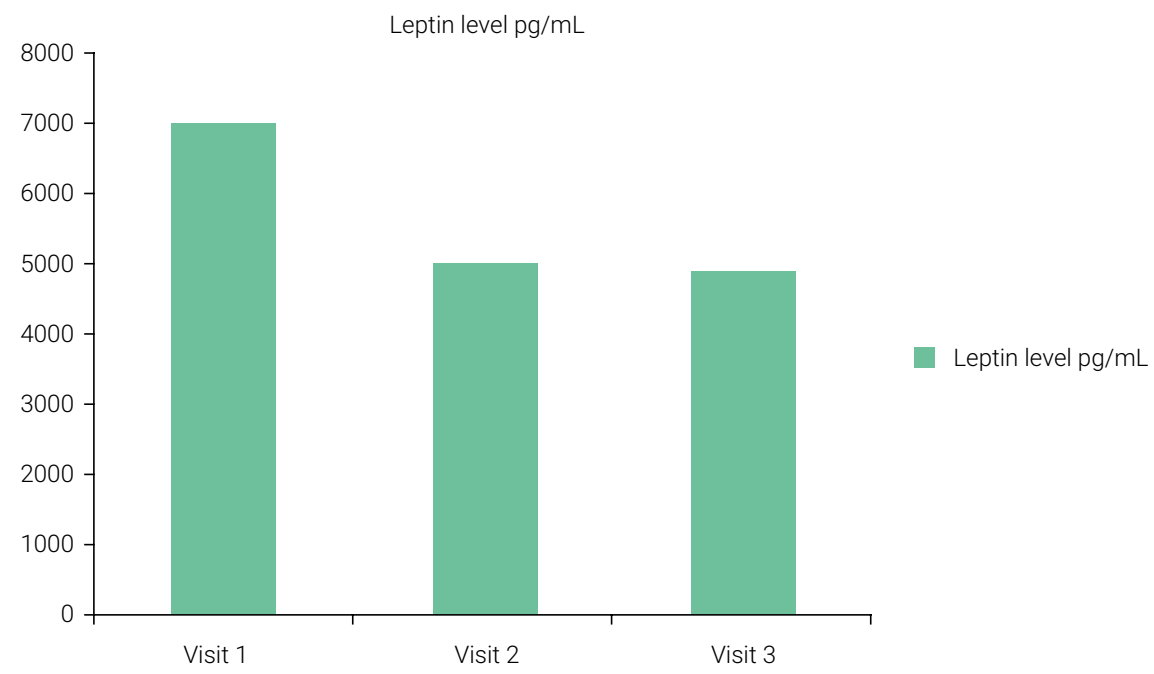

Figure 1. Saliva leptin level between the three visits

Table 3. Saliva leptin level differences between the three visits

\begin{tabular}{cccccccc}
\hline & Mean & $\begin{array}{c}\text { Std. } \\
\text { Deviation }\end{array}$ & $\begin{array}{c}\text { Std. Error } \\
\text { Mean }\end{array}$ & t & df & $\begin{array}{c}\text { Sig. } \\
\text { (2-tailed) }\end{array}$ \\
\hline Pair 1 & $\begin{array}{c}\text { Leptine 1 - } \\
\text { Leptine 2 }\end{array}$ & 1997.92900 & 734.59400 & 232.29902 & 8.601 & 9 & .000 \\
\hline Pair 2 & $\begin{array}{c}\text { Leptine 2- } \\
\text { Leptine 3 }\end{array}$ & 116.60500 & 341.15040 & 107.88123 & 1.081 & 9 & .308 \\
\hline Pair 3 & $\begin{array}{c}\text { Leptine 1 - } \\
\text { Leptine 3 }\end{array}$ & 2114.53400 & 804.44456 & 254.38771 & 8.312 & 9 & .000 \\
\hline
\end{tabular}

Data was analysed using paired t-test by the Statistical Package for the Social Sciences (SPSS 20).

Table 4. Changes in tooth movement after initial alignment

\begin{tabular}{|c|c|c|c|c|c|c|}
\hline \multicolumn{6}{|c|}{ One-Sample Statistics } & \multirow{2}{*}{$\begin{array}{l}95 \% \text { Confidence Interval } \\
\text { of the Difference }\end{array}$} \\
\hline & Mean & $\begin{array}{c}\text { Std. } \\
\text { Deviation }\end{array}$ & $t$ & df & $\begin{array}{c}\text { Sig. } \\
\text { (2-tailed) }\end{array}$ & \\
\hline $\begin{array}{l}\text { Tooth } \\
\text { movement }\end{array}$ & 2.2000 & .78881 & 8.820 & 9 & .000 & $(1.6357,2.7643)$ \\
\hline
\end{tabular}




\section{Discussion}

The result shows that, similar to leptin in gingival crevicular fluid, leptin in saliva also decreased in tooth movement. It does in some way potentially relate leptin as one of the mediators associated with tooth movement. This study opens a path to a bigger study with a larger sample size to further understand the role of leptin in orthodontics.

To certify that this leptin changes happen only due to tooth movement and not periodontal issues, in methodology, we emphasized on professional plaque control regime throughout the sample taking, as orthodontic treatment may negatively affect the periodontal health status ${ }^{16-19}$. As leptin was observed among patients with irreversible periodontal disease (periodontitis) ${ }^{20}$, patients with periodontitis were excluded from the study. Constant monitoring of the periodontium health was also done to ensure no patients develop periodontitis at the duration of study.

For saliva collection, the use of unstimulated saliva was implemented over the stimulated one to overcome the modulation of the fluid $\mathrm{pH}$ since the later provide less suitable saliva for diagnostic applications due to dilution in the concentration of the salivary protein of interest ${ }^{21}$

Two conclusions can be drawn:

- The concentration of leptin in the saliva is significantly decreased in time dependent manner in orthodontic tooth movement in alignment stage.

- Leptin may be one of the mediators associated with orthodontic tooth movement.

The knowledge gain from this study will enable us to have a better idea of the relationship between leptin and tooth movement and the role of this cytokine in controlling the local inflammation around the tooth.

\section{Acknowledgement:}

We would like to acknowledge International Islamic University Malaysia for grants given to carry out and publish this study: EDW-B-14-103-0988 and RIGS16-139-0303.

References:

1. Ahima RS, Flier JS. Leptin. Annu Rev Physiol. 2000;62:413-37.

2. Włodarski K, Włodarski P. Leptin as a modulator of osteogenesis. Ortop Traumatol Rehabil. 2009 Jan-Feb;11(1):1-6

3. Fantuzzi G, Faggioni R. Leptin in the regulation of immunity, inflammation, and hematopoiesis. J Leukoc Biol. 2000 Oct;68(4):437-46.

4. Wallace AM, Sattar N, Mcmillan D. The co-ordinated cytokine/hormone response to acute injury incorporates leptin. Cytokine. 2000 Jul;12(7):1042-5

5. Ducy P, Amling M, Takeda S, Priemel M, Schilling AF, Beil FT, et al. Leptin inhibits bone formation through a hypothalamic relay: a central control of bone mass. Cell. 2000 Jan 21;100(2):197-207.

6. Purwar P1, Khan MA, Mahdi AA, Pandey S, Singh B, Dixit J, Sareen S. Salivary and serum leptin concentrations in patients with chronic periodontitis. J Periodontol. 2015 Apr;86(4):588-94.doi: 10.1902/jop.2014.140581. 
7. Zhang Y, Proenca R, Maffei M, Barone M, Leopold L, Friedman JM. Positional cloning of the mouse obese gene and its human homologue. Nature. 1994 Dec 1;372(6505):425-32.

8. Bozkurt FY, Yetkin Ay Z, Sutçu R, Delibas, N, Demirel R. Gingival crevicular fluid leptin levels in periodontitis patients with long-term and heavy smoking. J Periodontol. 2006 Apr;77(4):634-40

9. Karthikeyan BV, Pradeep AR. Gingival crevicular fluid and serum leptin: their relationship to periodontal health and disease. J Clin Periodontol. 2007 Jun;34(6):467-72.

10. Reseland JE, Syversen U, Bakke I, Qvigstad G, Eide LG, Hjertner O, et al. Leptin is expressed in and secreted from primary cultures of human osteoblasts and promotes bone mineralization. J Bone Miner Res. 2001 Aug;16(8):1426-33

11. Nishijima Y, Yamaguchi M, Kojima T, Aihara N, Nakajima R, Kasai K. Levels of RANKL and OPG in gingival crevicular fluid during orthodontic tooth movement and effect of compression force on releases from periodontal ligament cells in vitro. Orthod Craniofac Res. 2006 May;9(2):63-70.

12. Alparslan D, Nihat K,Tugba A, F Nesibe, Meltem Z, Caglar B. Leptin levels in gingival crevicular fluid during orthodontics tooth movement Angle Orthod. 2010 May;80(3):504-8. doi: 10.2319/072109-402.1.

13. Thilander B, Rygh P, Reitan K. Tissue reactions in orthodontics. In Graber

14. TM. Orthodontics: current principles and techniques. Saint Louis: Mosby; 2000. p. 117-56.

15. Malamud D. Saliva as a diagnostic fluid. BMJ. 1992 Jul 25;305(6847):207-8.

16. O'Higgins EA, Lee RT. How much space is created from expansion or premolar extraction? J Orthod. 2000 Mar;27(1):11-3.

17. Zachriss BU, Alnaes L. Periodontal condition in orthodontically treated and untreated individuals. I. Loss of attachment, gingival pocket depth and clinical crown height. Angle Orthod. 1973 Oct; 43(4):402-11.

18. Alfuriji S, Alhazmi N, Alhamlan N, Al-Ehaideb A, Alruwaithi M, Alkatheeri N, et al. The effect of orthodontic therapy on periodontal health: a review of the literature. Int J Dent. 2014;2014:585048. doi: $10.1155 / 2014 / 585048$

19. Kouraki E, Bissada NF, Palomo JM, Ficara AJ. Orthodontic attachments on the gingival health of permanent second molars. Am J Orthod Dentofacial Orthop. 1991 Oct;100(4):337-40.

20. Kaufman E, Lamster IB. Gingival enlargement and resolution during and after orthodontic treatment. N Y State Dent J. 2005 Jun-Jul;71(4):34-7.

21. Purwar P1, Khan MA, Mahdi AA, Pandey S, Singh B, Dixit J, Sareen S. Salivary and serum leptin concentrations in patients with chronic periodontitis. J Periodontol. 2015 Apr;86(4):588-94. doi: 10.1902/jop.2014.140581.

22. RudneyJD, Kajander KC, Smith QT. Correlations between human salivary levels of lysozyme, lactoferrin, salivary peroxidase and secretory immunoglobulin A with different stimulatory states and over time. Arch Oral Biol. 1985;30(11-12):765-71. 